\title{
Genetic anomalies in fetuses with tetralogy of Fallot by using high-definition chromosomal microarray analysis
}

\author{
Ruan Peng, Ju Zheng, Hong-Ning Xie ${ }^{*} \mathbb{D}$, Miao He and Mei-Fang Lin
}

\begin{abstract}
Background: The etiology of TOF is complex and the genesis of TOF has been associated with environmental factors and genetic disorders, including chromosomal anomalies, aneuploidies, 22q11.2 deletion and single-gene disease. Previous literatures have shown that a chromosome alteration in about 30\% patients with TOF and recently published articles reported that 22q11.2 deletion syndrome accounts for $16 \%$ cases with TOF diagnosed postnatally. CMA now is considered as gold standard for detecting genetic anomalies in fetuses with congenital malformations. CMA could detect a $6.6-25 \%$ incremental yield of CNVs in CHDs. The aim of this study was to assess the genetic anomalies in fetal tetralogy of Fallot (TOF) by using high-definition CMA.

Methods: This retrospective study reviewed all the fetuses diagnosed with TOF between 2013 and 2018. Prenatal ultrasongraphic findings, including cardiac angle, and the findings of CMA using Affymetrix CytoScan HD array were collected.

Results: Ninety-six fetuses with TOF and known genetic results were enrolled. Right aortic arch was the most common associated anomalies (22.9\%). One fetus with trisomy 18, one with 46, XX, t (7;10)(q36;q22), one with 47, XYY and five with trisomy 21 were identified. Clinically significant CNVs occurred in $6.8 \%$ and uncertain significant CNVs in 3.4\% fetal TOF with normal karyotype. A total of four cases with 22q11.2 microdeletion and two fetuses with Yq11.223q11.23 microduplication have been identified. Genetic anomalies, including chromosomal aberrations and pathogenic CNVs, were significantly higher in the TOF with extracardiac anomaly group than in the TOF without extracardiac anomaly group $(P=0.005)$. Abnormal cardiac angle was noticed in $24.0 \%$ fetal TOF. Genetic anomalies were more common in the TOF with abnormal cardiac angle than with normal cardiac angle $(P=0.001)$. On the other hand, abnormal cardiac angle was noticed in $64.3 \%$ fetal TOF with genetic anomalies while abnormal cardiac angle occurred in $17.1 \%$ fetal TOF with normal genetic results $(P=0.001)$.
\end{abstract}

Conclusions: Genetic testing should be offered, specially using microarray analysis, for the fetal TOF with abnormal cardiac angle or extracardiac defects.

Keywords: Tetralogy of Fallot, 22q11.2 deletion, Chromosomal microarray analysis, Cardiac angle, Copy number variations

\footnotetext{
* Correspondence: hongning_x@126.com

Department of Ultrasonic Medicine, Fetal Medical Centre, The First Affiliated

Hospital of Sun Yat-sen University, Zhongshan Er Road 58\#, Guangzhou,

Guangdong, China
}

(c) The Author(s). 2019 Open Access This article is distributed under the terms of the Creative Commons Attribution 4.0 International License (http://creativecommons.org/licenses/by/4.0/), which permits unrestricted use, distribution, and reproduction in any medium, provided you give appropriate credit to the original author(s) and the source, provide a link to the Creative Commons license, and indicate if changes were made. The Creative Commons Public Domain Dedication waiver (http://creativecommons.org/publicdomain/zero/1.0/) applies to the data made available in this article, unless otherwise stated. 


\section{Background}

Fetal tetralogy of Fallot (TOF) and its variants comprise ventricular septal defect, overriding aorta and outflow obstruction of right ventricle, with an occurrence of about $8-12 \%$ in infants suffering with congenital heart diseases (CHDs) [1, 2]. A combination of anterocephalad deviation of the outlet septum and abnormal septoparietal trabeculations is now accepted as the hallmark of TOF [3]. The etiology of TOF is complex and the genesis of TOF has been associated with environmental factors and genetic disorders, including chromosomal anomalies, aneuploidies, 22q11.2 deletion and single-gene disease. Previous literatures have shown that a chromosome alteration in about $30 \%$ patients with TOF [4] and recently published articles reported that 22q11.2 deletion syndrome accounts for $16 \%$ cases with TOF diagnosed postnatally [5].

Chromosomal microarray analysis (CMA) was recently used to detect microdeletions and microduplications prenatally, which was called as copy number variations (CNVs), aiming to exclude fetuses with genetic syndrome. CMA now is considered as gold standard for detecting genetic anomalies in fetuses with congenital malformations. CMA could detect a $6.6-25 \%$ incremental yield of CNVs in CHDs [6-8] and subchromosomal rearrangements could interpret the molecular genesis of heart defects. TOF usually has a favor prognosis after operation, if genetic syndrome could be excluded. It is very important to provide information on the association of fetal TOF and genetic anomalies when prenatal counseling. However, the reports on the relationship between the fetal TOF and genetic anomalies, including chromosomal aberrations and pathogenic CNVs using CMA, are limited.

The aim of this study is to analyze the genetic findings in fetal TOF, and to assess that the association between coexisting anomalies and genetic anomalies, including chromosomal aberrations, 22q11.2 deletion and pathogenic CNVs or not.

\section{Material and methods}

This study reviewed all the fetuses that were diagnosed with TOF prenatally between 2013 and 2018 in our institution. Prenatal ultrasonographic presentations of TOF are as follows: ventricular septal defect, right ventricular outflow obstruction and an overriding aorta. In this study, three major types of fetal TOF were enrolled, including TOF with pulmonary stenosis, TOF with pulmonary atresia and TOF with an absent pulmonary valve syndrome. A detailed ultrasound screening, including evaluation of intracardiac anatomy and extracardiac structure, was performed in each case. After two dimensional echocardiography examinations, fetal cardiac volumes were acquired with spatiotemporal image correlation (STIC) through the thorax and stored. Fetal cardiac angles were measured by the operator who had no knowledge of the genetic results. The four-chamber view, which showed the interventricular septum, body of the spine and the sternum clearly, was chosen for measurement. Cardiac angle was defined as the angle between the line going through the sternum and the body of the spine and the line tracing the ventricular septum (Fig. 1). Specially, the line goes through the sternum and the body of the spine should bisect the thorax into two equal parts. We made measurements of the cardiac angle at the end of systole period when the mitral valve and the tricuspid valve was closed. A frozen frame from real time images or stored volume data sets could be used for measurement of the cardiac angle. If cardiac angle was within the range $45 \pm 20^{\circ}$, it would be considered as normal [9]. A detailed pre-test and post-test counseling was provided in all participants and written informed consents were obtained in all patients. The Ethics Committee of the institution has approved this study. According to the coexisting extracardiac defects, fetuses with TOF were divided into two groups: one group with extracardiac defects (TOF-extra) and the other group without extracardiac defects (TOF-no extra). According to the cardiac angle, fetal TOF was divided into TOF with normal cardiac angle (TOF-CAn) group and TOF with abnormal cardiac angle group (TOF-CAab).

Prenatal samples were processed by microarray-CGH (comparative genomic hybridization) and SNP array (single-nucleotide polymorphism) using Affymetrix CytoScan HD array platform (Affymetrix Inc., Santa Clara, CA, USA) for whole genome-wide analysis. Fetal DNA from cultured amnion or cord blood cells was analyzed for detection of copy number gains or losses. Microarray

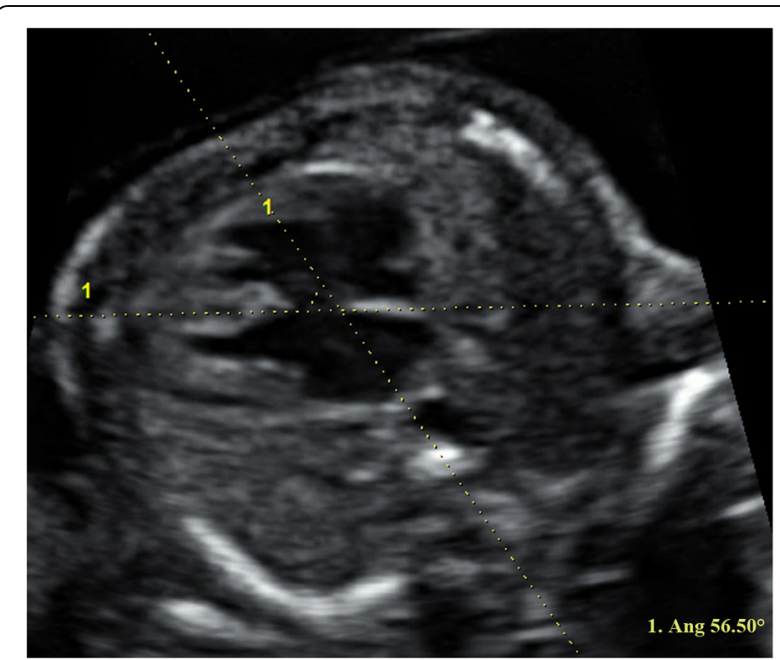

FIG. 1 Two dimensional image showing measurement of the cardiac angle in a fetus with tetralogy of Fallot at end systole of the cardiac cycle. Chromosomal microarray analysis revealed that no microdeletion or microduplication was identified in this case and the fetus was delivered at 36 gestational weeks 
analysis was performed with the Affymetrix Chromosome Analysis Suite (ChAS) software. The interpretation of copy number gains or losses was performed as follows: First, the detected CNVs were compared with our own database. Then, public available databases, for example, DGV, OMIM, NCBI Gene, DECIPHER, ISCA, CHDWiki, PubMed and so on, were compared. Published literatures were also reviewed when necessary. The detected CNVs were classified into benign CNVs, CNVs of unclear significance (VOUS) and pathological CNVs. Clinically significant CNVs are defined as those that are de novo, relatively large size, and/or contained clinically relevant genes or are associated with well-established syndromes [10]. Furthermore, all CNVs were confirmed with quantitative fluorescent Polymerase Chain Reaction (QF-PCR) or fluorescence in situ hybridization (FISH) when necessary.

Fetal cardiac angle, ultrasonographic findings, genetic results and perinatal outcomes were obtained and recorded. Postnatal echocardiography, surgery or autopsy was obtained in almost all cases.

Mann-Whitney U test was used to compare continuous variables between different groups. Chi-square test or Fisher's exact test was performed for comparisons of categorical variables between different groups. The software package of SPSS version 22.0 (SPSS Inc., Chicago, IL, USA) was used for statistical analysis. $P$ value of $<0.05$ was considered as significant.

\section{Results}

One hundred and twenty-four fetuses were suspected with TOF prenatally between 2013 and 2018, with a median gestational age of $23^{+1}$ weeks. Genetic data or postnatal data could not be obtained in twenty-six cases. Two suspected cases were confirmed as ventricular septal defect by postnatal echocardiography and so these two cases were excluded. A total of ninety-six confirmed fetuses with TOF were enrolled and genetic results and clinical outcomes were collected in all these 96 fetuses, including 80 TOF with pulmonary stenosis, 14 TOF with pulmonary atresia and two TOF with an pulmonary valve absent syndrome (Table 1). Fetal TOF with extracardiac defects (TOF-extra) were identified in 49 (51.0\%, 49/96) cases and TOF without extracardiac defects (TOF-no extra) were identified in $47(49.0 \%, 47 / 96)$ cases. The associated extracardiac defects in the fetuses with TOF are shown in Table 2. Furthermore, coexisting intracardiac anomalies were noticed in $43.8 \%$ (42/96) fetal TOF and right aortic arch was the most common coexisting anomaly, with an incidence rate of $22.9 \%$ (22/96). The type, number and frequency of associated cardiac anomalies are listed in Table 3. An absent ductus arteriosus was also seen in fourteen cases $(14.6 \%, 14 / 96)$. The median of cardiac angle was $50.3^{\circ}$ (range from $26.7^{\circ}$ to $81.1^{\circ}$ ). Normal cardiac angle was detected in $76.0 \%(73 / 96)$ cases and the
Table 1 Demographic characteristics of fetuses with prenatal diagnosis of TOF

\begin{tabular}{ll}
\hline Characteristic & Value \\
\hline Maternal age (years) & $30(19 \sim 42)$ \\
Gestational age at diagnosis (weeks) & $23^{+1}\left(16^{+2} \sim 31^{+4}\right)$ \\
TOF type & \\
TOF with pulmonary stenosis & $80(83.3 \%)$ \\
TOF with pulmonary atresia & $14(14.6 \%)$ \\
TOF with an pulmonary valve absent syndrome & $2(2.1 \%)$ \\
Extracardiac anomaly diagnosed prenatally & $49(51.0 \%)$ \\
Intracardiac defects & $42(43.8 \%)$ \\
Abnormal karyotype & $8(83.3 \%)$ \\
Termination of pregnancy & $44(45.8 \%)$ \\
Selective reduction & $14(14.6 \%)$ \\
Livebirth & $35(36.5 \%)$ \\
\hline
\end{tabular}

Data are reported as median (range) or $n(\%)$

Table 2 Associated extracardiac defects in fetuses with TOF

\begin{tabular}{ll}
\hline Extracardiac defects & $n(\%)$ \\
\hline Hypoplasia of the nasal bone & $15(15.6 \%)$ \\
Short long bone & $10(10.4 \%)$ \\
Fetal growth restriction & $9(9.4 \%)$ \\
Single umbilical artery & $8(8.3 \%)$ \\
Hypoplasia of the thymus & $6(6.3 \%)$ \\
Nuchal fold thickening ( $\geq 6 \mathrm{~mm})$ & $6(6.3 \%)$ \\
Ventriculomegaly & $5(5.2 \%)$ \\
Heterogeneous echo pattern of liver & $4(4.2 \%)$ \\
Hypoplasia of phalanx & $4(4.2 \%)$ \\
Echogenic bowl & $3(3.1 \%)$ \\
Echogenic kidneys & $2(2.1 \%)$ \\
Club foot & $1(1.0 \%)$ \\
Omphalocele & $1(1.0 \%)$ \\
Low-set ears & $1(1.0 \%)$ \\
Overlapping fingers & $1(1.0 \%)$ \\
Arachnoid cyst & $1(1.0 \%)$ \\
Micrognathia & $1(1.0 \%)$ \\
Ectrodactylia & $1(1.0 \%)$ \\
Cystic hygroma & $1(1.0 \%)$ \\
Strawberry-shaped skull & $1(1.0 \%)$ \\
Long-eyebrows & $1(1.0 \%)$ \\
Hypoplasia of the lung & $1(1.0 \%)$ \\
Esophago-tracheal fistula & $1(1.0 \%)$ \\
Hexencephaly & $1(1.0 \%)$ \\
\hline & $1(1.0 \%)$ \\
\hline & $1(1.0 \%)$ \\
\hline
\end{tabular}


Table 3 The type, number and frequency of coexisting cardiac anomalies in fetuses with TOF

\begin{tabular}{ll}
\hline Intracardiac anomalies & $n(\%)$ \\
\hline Right aortic arch & $22(22.9)$ \\
Not present or visualized ductus arteriosus & $14(14.6)$ \\
Persistent left superior vena cava & $8(8.3)$ \\
Endocardial cushion defect & $6(6.3)$ \\
Aberrant right subclavian artery & $1(1.0)$ \\
Major aortopulmonary collaterals & $1(1.0)$ \\
Left pulmonary artery sling & $1(1.0)$ \\
Tricuspid atresia & $1(1.0)$ \\
\hline
\end{tabular}

remaining $24.0 \%(23 / 96)$ cases were identified as an abnormal cardiac angle.

Among the 96 fetal TOF with known chromosomal karyotype, eight fetuses were confirmed with chromosomal anomalies, including one with trisomy 18, one with 46, XX, t(7;10)(q36;q22), one with 47, XYY and five with trisomy 21. Chromosomal microarray analysis also verified the chromosomal aberrations in these seven fetuses with unbalanced rearrangement. On microarray, pathogenic CNVs was demonstrated in 6.8\% (6/88) fetal TOF with normal karyotype. In our study, a total of four cases with 22q11.2 microdeletion and two fetuses with Yq11.223q11.23 microduplication have been identified. In addition, uncertain significant microdeletions or microduplications were detected in $3.4 \%$ (3/88). Benign CNVs also detected in four cases (case 41, case 42, case 72 and case 81). The prenatal ultrasound findings, genetic results and clinical outcomes in these eight fetal TOF with abnormal karyotype and nine with copy variations of uncertain significance or pathogenicity on microarray analysis are shown in Tables 4 and 5. In conclusion, genetic anomalies occurred in 14.6\% (14/96) fetal TOF, including chromosomal aberrations and pathogenic CNVs.

Excluding fetuses that underwent selective reduction or termination of pregnancies, the overall survival rate was $92.1 \%$ (35/38) because three fetuses suffered with intrauterine death. Survival rate was not significantly different between TOF with extracardiac defects (TOF-extra) group and the TOF without extracardiac defects (TOF- no extra) group. Genetic anomalies, including chromosomal aberrations and pathogenic CNVs, were significantly higher in the TOF-extra group than in the TOF-no extra group $(P=0.005)$. However, the incidence rate of intracardiac anomalies, the incidence rate of variations of uncertain significance (VOUS) and cardiac angles were not statistically different between these two groups. More details of these two groups are shown in Table 6. Prevalence rate of genetic anomalies had no significant difference between fetal TOF with intracaridac anomalies $(16.7 \%, 7 / 42)$ and fetal TOF without intracardiac anomalies $(13.0 \%, 7 / 54)(P=0.610)$.

In our data, genetic anomaly was more common in the fetal TOF with abnormal cardiac angle (TOF-CAab) group than in the fetal TOF with normal cardiac angle (TOF-CAn) group, with a rate of $39.1 \%(9 / 23)$ and $6.8 \%$ (5/73), respectively $(P=0.001)$. In the other side, abnormal cardiac angle was noticed in $64.3 \%(9 / 14)$ fetal TOF

Table 4 The prenatal ultrasound findings and clinical outcomes in the eight fetuses with TOF and chromosomal abnormalities

\begin{tabular}{|c|c|c|c|c|c|c|}
\hline Case & Intracardiac anomalies & Extracardiac defects & Fetal karyotype & CMA findings & $\begin{array}{l}\text { Pathological } \\
\text { significance }\end{array}$ & Outcome \\
\hline 2 & Right aortic arch & Ventricularmegaly & 47, XYY & $\operatorname{arr}[h g] X \times 1, Y \times 2$ & Yes & Survival \\
\hline 25 & - & $\begin{array}{l}\text { Hypoplasia of the nasal bone, } \\
\text { short long bone, nuchal fold } \\
\text { thickening }\end{array}$ & $47, X X,+21$ & $\begin{array}{l}\operatorname{arr} 21 q 11.2 q 22.3(15,190,686- \\
48,097,372) \times 3\end{array}$ & Yes & $\begin{array}{l}\text { Selective } \\
\text { reduction }\end{array}$ \\
\hline 26 & - & $\begin{array}{l}\text { Strawberry-shaped skull, long- } \\
\text { eyebrows, overlapping fingers, } \\
\text { hypoplasia of the thymus }\end{array}$ & $47, X X,+18$ & $\begin{array}{l}\operatorname{arr} 18 p 11.32 q 23(136,227- \\
78,013,728) \times 3\end{array}$ & Yes & $\mathrm{TOP}$ \\
\hline 34 & Endocardial cushion defect & $\begin{array}{l}\text { Ventricularmegaly, hypoplasia of } \\
\text { the nasal bone, short lone bone, } \\
\text { echogenic bowl }\end{array}$ & $47, X Y,+21$ & $\begin{array}{l}\operatorname{arr} 21 q 11.2 q 22.3(15,190,868- \\
48,097,372) \times 3\end{array}$ & Yes & TOP \\
\hline 43 & - & $\begin{array}{l}\text { Ventricularmegaly, hypoplasia of } \\
\text { the nasal bone, hypoplasia of the } \\
\text { phalanx, short long bone }\end{array}$ & $47, X Y,+21$ & $\begin{array}{l}\operatorname{arr} 21 q 11.2 q 22.3(15,190,868- \\
48,097,372) \times 3\end{array}$ & Yes & TOP \\
\hline 50 & $\begin{array}{l}\text { Right aortic arch, ductus } \\
\text { arteriosus not visualized }\end{array}$ & Nuchal fold thickening & $47, X Y,+21$ & $\begin{array}{l}\operatorname{arr} 21 q 11.2 q 22.3(15,190,868- \\
48,097,372) \times 3\end{array}$ & Yes & Survival \\
\hline 88 & - & $\begin{array}{l}\text { Hypoplasia of the nasal bone, } \\
\text { short long bone, nuchal fold } \\
\text { thickening, echogenic bowl }\end{array}$ & $47, X Y,+21$ & $\begin{array}{l}\operatorname{arr} 21 q 11.2 q 22.3(15,190,868- \\
48,097,372) \times 3\end{array}$ & Yes & TOP \\
\hline 93 & - & $\begin{array}{l}\text { Hypoplasia of the nasal bone, } \\
\text { short long bone }\end{array}$ & $46, X X, t(7 ; 10)(q 36 ; q 22)$ & $\operatorname{arr}[h g](1-22) \times 2, x \times 2$ & - & TOP \\
\hline
\end{tabular}


Table 5 Characteristic of the fetuses with copy number variants detected by chromosomal microarray analysis among 88 fetuses with TOF and normal karyotype

\begin{tabular}{|c|c|c|c|c|c|c|}
\hline Case & Intracardiac anomalies & Extracardiac defects & Fetal karyotype & CMA findings & $\begin{array}{l}\text { Pathological } \\
\text { significance }\end{array}$ & Outcome \\
\hline 8 & $\begin{array}{l}\text { Right aortic arch, } \\
\text { persistent left superior } \\
\text { vena cava }\end{array}$ & Hypoplasia of the thymus & $46, X X$ & $\begin{array}{l}\operatorname{arr} 22 q 11.21(18,916,842-21,798,907) \times 1, \\
2.882 \mathrm{Mb}\end{array}$ & Yes & TOP \\
\hline 3 & $\begin{array}{l}\text { Persistent left superior } \\
\text { vena cava, aberrant right } \\
\text { subclavian artery }\end{array}$ & - & $46, X Y$ & $\begin{array}{l}\operatorname{arrYq11.223q11.23~}(24,988,143-28,423,925) \\
\times 2,3.436 \mathrm{Mb}\end{array}$ & Yes & $\begin{array}{l}\text { Selective } \\
\text { reduction }\end{array}$ \\
\hline 19 & - & Single umbilical artery & $46, X X$ & arr2p24.3 $(13,529,731-14,360,751) \times 3,831 \mathrm{~Kb}$ & VOUS & TOP \\
\hline 35 & - & - & $46, X Y$ & $\begin{array}{l}\operatorname{arrYq11.223q11.23~}(24,651,462-28,423,925) \times 2 \\
\text { 3.772 Mb }\end{array}$ & Yes & Survival \\
\hline 46 & - & $\begin{array}{l}\text { Single umbilical artery, } \\
\text { hypoplasia of the nasal } \\
\text { bone, heterogeneous } \\
\text { echo pattern of the liver }\end{array}$ & $46, X X$ & arr16p13.3 $(1,988,121-2,551,691) \times 3,564 \mathrm{~Kb}$ & VOUS & IUD \\
\hline 51 & - & - & $46, X Y$ & $\begin{array}{l}\text { arr8p23.3 }(1,974,181-2,193,914) \times 1,219 \mathrm{~Kb} ; \\
\text { arr8p23.2 }(2,202,357-2,730,902) \times 3,529 \mathrm{~Kb} ; \\
\text { arr14q11.2 }(22,624,119-22,940,347) \times 1,316 \mathrm{~Kb}\end{array}$ & $\begin{array}{l}\text { VOUS, VOUS, } \\
\text { benign }\end{array}$ & TOP \\
\hline 62 & - & $\begin{array}{l}\text { Hypoplasia of the } \\
\text { thymus, low-set ears }\end{array}$ & $46, X X$ & $\begin{array}{l}\text { arr } 22 q 11.21(18,916,842-21,465,659) \times 1, \\
2.549 \mathrm{Mb}\end{array}$ & Yes & $\begin{array}{l}\text { Selective } \\
\text { reduction }\end{array}$ \\
\hline 67 & Right aortic arch & Nuchal thickening & $46, X Y$ & $\begin{array}{l}\text { arr 22q11.21 }(18,916,842-21,798,907) \times 1, \\
2.882 \mathrm{Mb}\end{array}$ & Yes & TOP \\
\hline 95 & Right aortic arch & Hypoplasia of the thymus & $46, X Y$ & $\begin{array}{l}\operatorname{arr} 22 q 11.21(18,636,749-21,800,471) \times 1 \text {, } \\
3.164 \mathrm{Mb}\end{array}$ & Yes & TOP \\
\hline
\end{tabular}

CMA chromosomal microarray analysis, TOP termination of pregnancy, VOUS variations of uncertain significance, IUD intrauterine death

with genetic anomalies while abnormal cardiac angle occurred in $17.1 \%(14 / 82)$ fetal TOF with normal genetic results $(P=0.001)$. Conversely, the difference of the survival rate, the incidence rate of intracardiac anomalies, the incidence rate of extracardiac anomalies and the detection rate of VOUS did not reach statistical significance between the TOF-CAab group and the TOF-CAn group. Prevalence rate of genetic anomalies was not significantly different between TOF with pulmonary atresia $(7.1 \%, 1 / 14)$, TOF with pulmonary stenosis $(16.3 \%, 13 / 80)$ and TOF with an absent pulmonary valve syndrome $(0 \%, 0 / 2)(P=0.565)$. Prenatal ultrasound findings, genetic results with CMA and postnatal outcomes in TOF-CAab group and TOF-CAn group are listed in Table 7.

\section{Discussion}

To the best of our knowledge, our study was one of the largest to evaluate the fetuses with TOF and the associated genetic anomalies. In this study, prenatal ultrasound characteristics, genetic results and clinical outcomes were reviewed and analyzed in 96 fetuses with TOF. TOF was one of the commonest congenital heart disease in cyanosis. Glessner et al. found an increased prevalence of de novo CNVs in cases with conotruncal malformations [11]. Our data showed that pathogenic CNVs occurred in $6.8 \%$ fetal TOF and the published article demonstrated that pathogenic subchromosomal arrangements were identified in $5.3 \%$ of conotruncal heart defects in our institution [12]. However, the incremental yield of microarray analysis

Table 6 Characteristics and genetic results in fetal TOF with extracardiac defects (TOF-Extra) group and in fetal TOF without extracardiac defects (TOF-no Extra) group

\begin{tabular}{llll}
\hline Characteristics & TOF-Extra $(N=49)$ & TOF-no Extra $(N=47)$ & $P$ value \\
\hline Maternal age, years & $31(19 \sim 42)$ & $31(21 \sim 38)$ & 0.773 \\
Gestational age at diagnosis, weeks & $22^{+6}\left(16^{+2} \sim 30^{+1}\right)$ & $23^{+2}\left(18^{+5} \sim 31^{+4}\right)$ & 0.422 \\
Intracardiac anomalies (\%) & $49.0(24 / 49)$ & $38.3(18 / 47)$ & 0.292 \\
Genetic anomalies (\%) & $24.5(12 / 49)$ & $4.3(2 / 47)$ & 0.005 \\
VOUS (\%) & $4.1(2 / 49)$ & $2.1(1 / 47)$ & 1.000 \\
Cardiac angle $\left(^{\circ}\right)$ & $50.4(25.7 \sim 73.4)$ & $50.2(29.2 \sim 81.1)$ & 0.613 \\
Abnormal cardiac angle (\%) & $26.5(13 / 49)$ & $21.3(10 / 47)$ & 0.547 \\
Survival rate $(\%)$ & $87.5(14 / 16)^{\mathrm{a}}$ & $95.5(21 / 22)^{\mathrm{a}}$ & 0.562 \\
\hline
\end{tabular}

${ }^{a}$ Cases that underwent selective reduction or termination of pregnancies were excluded. VOUS, variations of uncertain significance 
Table 7 Prenatal ultrasound findings, genetic results and postnatal outcomes in fetal TOF with a normal cardiac angle group (TOF-CAn) and in fetal TOF with an abnormal cardiac angle group (TOF-CAab)

\begin{tabular}{|c|c|c|c|}
\hline Characteristics & TOF-CAn $(N=73)$ & TOF-CAab $(N=23)$ & $P$ value \\
\hline Maternal age, years & $30(20 \sim 42)$ & 30 (19 38) & 0.619 \\
\hline Gestational age at diagnosis, weeks & $23^{+3}\left(16^{+2} \sim 30^{+3}\right)$ & $22^{+6}\left(18^{+5} \sim 31^{+4}\right)$ & 0.955 \\
\hline \multicolumn{4}{|l|}{ TOF type } \\
\hline TOF-pulmonary valve atresia (\%) & $13.0(11 / 73)$ & $14.3(3 / 23)$ & \multirow[t]{3}{*}{0.695} \\
\hline TOF-pulmonary valve stenosis (\%) & $82.2(60 / 73)$ & $87.0(20 / 23)$ & \\
\hline TOF-an absent pulmonary valve syndrome (\%) & $2.7(2 / 73)$ & $0(0 / 23)$ & \\
\hline Intracardiac anomalies (\%) & $43.8(32 / 73)$ & $39.1(9 / 23)$ & 0.691 \\
\hline Extracardiac defects (\%) & $50.7(37 / 73)$ & $52.2(12 / 23)$ & 0.901 \\
\hline Genetic anomalies (\%) & $6.8(5 / 73)$ & $39.1(9 / 23)$ & 0.001 \\
\hline VOUS (\%) & $1.4(1 / 73)$ & $8.7(2 / 23)$ & 0.142 \\
\hline Survival rate (\%) & $85.7(18 / 19)^{\mathrm{a}}$ & $88.9(17 / 19)^{\mathrm{a}}$ & 1.000 \\
\hline
\end{tabular}

${ }^{a}$ Cases that underwent selective reduction or termination of pregnancies were excluded. VOUS, variations of uncertain significance

was lower than the meta-analysis study, which reported that an incremental yield of $12 \%$ in fetuses with CHDs [13]. So, we do not have sufficient evidence to make a conclusion that pathogenic CNVs are more common in conotruncal heart defects.

Chromosome 22q11.2 deletion syndrome, which is also called as DeGorge Syndrome, is the second most common cause of CHD, with a rate of 0 to $18 \%$ in different types of CHDs $[4,14-16]$. TOF, interrupted aortic arch, ventriculoseptal defect and truncus arteriosus are the most common cardiac anomalies in patients with 22q11.2 deletion syndrome. Our findings demonstrated that $22 \mathrm{q} 11.2$ microdeletion was identified in $4.2 \%(4 / 96)$ fetal TOF. The reported rates of 22q11.2 deletion in TOF were varying from 0 to $18 \%[4,16,17]$. A metaanalysis study demonstrated that $18.6 \%$ of fetal TOF was complicated with 22q11.2 deletion [18] and TOF with pulmonary stenosis was more frequently associated with major chromosomal anomalies, while 22q11.2 deletion syndrome occurred more common in fetal TOF with pulmonary atresia and TOF with an absent pulmonary valve syndrome [18]. In our series, prevalence rates of chromosomal anomalies and 22q11.2 deletion were not significantly different among TOF with pulmonary atresia, TOF with pulmonary stenosis and TOF with an absent pulmonary valve syndrome. The reason may be that the sample size of TOF with atresia and TOF with an absent pulmonary valve syndrome was relatively small.

A significant proportion of the patients were detected with extracardiac anomalies and coexisting with extracardiac anomaly significantly increased the risk for genetic anomalies. A detailed ultrasound evaluation is recommended to exclude extracardiac anomalies, especially to exclude soft markers and hypoplasia of the thymus, and genetic testing with CMA is suggested when coexisting with extracardiac defects. Just as the recommendations published by the American College of Obstetricians and Gynecologists and the Society for Maternal-Fetal Medicine, the fetuses with one or more major structural abnormalities was suggested to perform invasive prenatal diagnosis using chromosomal microarray analysis [19]. Abnormal cardiac angle may be caused by congenital heart diseases [9], congenital diaphragmatic hernia, [20] abdominal wall defects, [21] occupying lesions such as bronchopulmonary sequestration [22] and so on. Conotruncal malformations may coexist with an abnormal cardiac angle. The study of Zhao demonstrated that the cardiac angle was abnormal in $11.6 \%$ out of the 527 cases with CHDs if doing measurement at end systole and they reported that the CHDs with right ventricular volume overload held the highest incidence of abnormal cardiac angle [23]. Abnormal cardiac angle may be caused by the external forces and genetic and molecular markers [24]. The relationship between abnormal cardiac angle and chromosomal anomalies has been reported [25]. Leftward rotation of the fetal cardiac was more severely in fetuses with CHDs and 22q11.2 deletion syndrome when comparing with those with CHDs but no 22q11.2 deletion syndrome [25]. In our cohort, levorotation of the cardiac was noticed in the fetuses with chromosomal aberrations, 22q11.2 deletion syndrome and pathogenic CNVs. The mechanism of leftward rotation in fetuses with 22q11.2 deletion and aneuplodies has been speculated as that was due to the aplasia or hypoplasia of the thymus.

In this study, uncertain significant submicroscopic chromosomal arrangements have been revealed in three cases. In case 19, a 831-Kb microduplication in chromosome 2 p24.3 was revealed in the fetus with TOF and single umbilical artery. The gains have not been reported in the normal population. The parents opted for termination of pregnancy because of the cardiac defects. We made a conclusion that the $831-\mathrm{Kb}$ microduplication in 
this case was VOUS. Case 46 exhibited a 564-Kb microduplication on the band of chromosome 16p13.3 in the fetus with TOF, single umbilical artery, hypoplasia of the nasal bone and heterogeneous echo pattern of the liver. Unfortunately, the fetus suffered with intrauterine death. The deletion region comprises TSC2, PKD1, TBC1D24 and $A B C A 3$ genes and mutations of these genes are associated with tuberous sclerosis complex, autosomal dominant polycystic kidney disease type 1 (ADPKD1) or familial infantile myoclonic epilepsy. A $219-\mathrm{Kb}$ deletion in chromosome 8p23.3, a 529-Kb duplication of chromosomal 8p23.2 and a $316-\mathrm{Kb}$ deletion of chromosome $14 \mathrm{q}$ was revealed in case 51. However, ultrasonographic finding of this case was isolated TOF. Phenotype of the reported cases partially overlapping 8p23.3 included hypoplasia of the corpus callosum, delayed speech and language development, intellectual disability, and so on. The deletion region of this case has not been found in DGV, DECIPHER or ISCA. The search for $8 \mathrm{p} 23.2$ identified the similar results. The pregnancy was also terminated. In our institution, parents usually choose to terminate the pregnancies with TOF, even though the microdeletions or microduplications are interpreted as VOUS prenatally. The study of Shanshen E aimed to identify potential novel CHD candidate genes and they demonstrated that a high incidence of abnormal genes identified by CMA in CHD patients, including many CNVs of "unknown clinical significance" [26]. Clinical and laboratory evidence is need for confirmation the pathogenicity of CNVs of VOUS.

There were several limitations of this study. Firstly, the retrospective design of this study limited that all the cardiac angles were measured retrospectively. Secondly, two of the three fetuses with TOF and uncertain significant CNVs opted for termination of pregnancies. Phenotype after delivery and long-term prognosis, such as cognitive performance or motor development, were not available in these two cases.

\section{Conclusions}

In summary, the findings of this study demonstrated that clinically significant microdeletions or microduplications occurred in $6.8 \%$ and uncertain significant CNVs was detected in $3.4 \%$ fetal TOF with normal karyotype. Genetic anomalies were more commonly associated with extracardiac anomalies and abnormal cardiac angle. A detailed ultrasonographic assessment, including intracardiac and extracardiac structures, should be performed in the fetus with TOF. We would therefore advocate that genetic testing with chromosomal microarray analysis should be recommended and offered when a fetal TOF coexists with extracardiac defects or abnormal cardiac angle.

\section{Abbreviations}

CHDs: congenital heart diseases; CMA: chromosomal microarray analysis; CNVs: copy number variations; STIC: spatiotemporal image correlation; TOF: Tetralogy of Fallot; VOUS: variations of uncertain significance

\section{Acknowledgements}

We are particularly grateful for the consent and participation of the patients.

\section{Funding}

This study was supported by research grant 81501491 and 81571687 from the National Scientific Foundation Committee of China.

\section{Availability of data and materials}

The datasets used or analysed during the current study are available from the corresponding author on reasonable request.

\section{Authors' contributions}

RP: Data Collection, Manuscript writing. JZ: Data analysis, Manuscript editing. HNX: Project development. MH: Data management, Manuscript editing. MFL: Data analysis, Manuscript editing. All authors read and approved the final manuscript.

Ethics approval and consent to participate

The Ethics Committee of the institution has approved this study. Written informed consents were obtained in all patients.

Consent for publication

All of the authors confirmed that they agreed with the publication of our manuscript.

\section{Competing interests}

The authors declare that they have no competing interests.

\section{Publisher's Note}

Springer Nature remains neutral with regard to jurisdictional claims in published maps and institutional affiliations.

Received: 8 March 2019 Accepted: 24 April 2019

Published online: 06 May 2019

\section{References}

1. Mitchell SC, Korones SB, Berendes HW. Congenital heart disease in 56,109 births. Incidence and natural history. Circulation. 1971;43(3):323-32.

2. Allan L. Prenatal diagnosis of structural cardiac defects. Am J Med Genet. 2007;145(1):73-6.

3. Restivo A, Anderson RH, Carletti R, et al. Correlating the morphological features of tetralogy of Fallot and the Eisenmenger malformation. Cardiol Young. 2017;27(1):161-72.

4. Bellucco FT, Belangero SI, Farah LM, et al. Investigating 22q11.2 deletion and other chromosomal aberrations in fetuses with heart defects detected by prenatal echocardiography. Pediatr Cardiol. 2010;31(8):1146-50.

5. McDonald-McGinn DM, Tonnesen MK, Laufer-Cahana A, et al. Phenotype of the 22q11.2 deletion in individuals identified through an affected relative: cast a wide FISHing net! Genet Med. 2001;3(1):23-9.

6. Yan $Y$, Wu Q, Zhang $L$, et al. Detection of submicroscopic chromosomal aberrations by array-based comparative genomic hybridization in fetuses with congenital heart disease. Ultrasound Obstet Gynecol. 2014; 43(4):404-12.

7. Liao C, Li R, Fu F, et al. Prenatal diagnosis of congenital heart defect by genome-wide high-resolution SNP array. Prenat Diagn. 2014;34(9):858-63.

8. Schmid M, Stary S, Blaicher W, et al. Prenatal genetic diagnosis using microarray analysis in fetuses with congenital heart defects. Prenat Diagn. 2012;32(4):376-82

9. ISUOG Education Committee. Cardiac screening examination of the fetus: guidelines for performing the 'basic' and 'extended basic' cardiac scan. Ultrasound Obstet Gynecol. 2006;27(1):107-13.

10. Fiorentino F, Caiazzo F, Napolitano S, et al. Introducing array comparative genomic hybridization into routine prenatal diagnosis practice: a prospective study on over 1000 consecutive clinical cases. Prenat Diagn. 2011;31(13):1270-82. 
11. Glessner JT, Bick AG, Ito K, et al. Increased frequency of de novo copy number variants in congenital heart disease by integrative analysis of single nucleotide polymorphism array and exome sequence data. Circ Res. 2014; 115:884-96.

12. Lin $\mathrm{M}$, Zheng J, Peng R, Du L, et al. Prenatal diagnosis of chromosomal aberrations in fetuses with conotruncal heart defects by genome-wide high resolution SNP array. J Matern Fetal Neonatal Med. 2018;20:1-7.

13. Jansen $F A$, Blumenfeld $Y$ J, Fisher $A$, et al. Array comparative genomic hybridization and fetal congenital heart defects: a systematic review and meta-analysis. Ultrasound Obstet Gynecol. 2015;45(1):27-35.

14. Li Z, Huang J, Liang B, et al. Copy number variations in the GATA4, NKX2-5, TBX5, BMP4 CRELD1 and 22q11.2 gene regions in Chinese children with sporadic congenital heart disease. J Clin Lab Anal. 2019;33(2):e22660. https://doi.org/10.1002/jcla.22660.

15. Miranda JO, Callaghan N, Miller O, et al. Right aortic arch diagnosed antenatally: associations and outcome in 98 fetuses. Heart. 2014;100(1):54-9.

16. Kaguelidou F, Fermont L, Boudjemline Y, et al. Foetal echocardiographic assessment of tetralogy of Fallot and postnatal outcome. Eur Heart J. 2008; 29(11):1432-8.

17. Song MS, Hu A, Dyamenahalli U, et al. Extracardiac lesions and chromosomal abnormalities associated with major fetal heart defects: comparison of intrauterine, postnatal and postmortem diagnoses. Ultrasound Obstet Gynecol. 2009;33(5):552-9.

18. Zhao Y, Abuhamad A, Fleenor J, et al. Prenatal and postnatal survival of fetal tetralogy of Fallot: a meta-analysis of perinatal outcomes and associated genetic disorders. J Ultrasound Med. 2016;35(5):905-15.

19. Committee Opinion No. 581. The use of chromosomal microarray analysis the prenatal diagnosis. Obstet Gynecol. 2013;122:1374-7.

20. Van Mieghem T, Gucciardo L, Doné $E$, et al. Left ventricular cardiac function in fetuses with congenital diaphragmatic hernia and the effect of fetal endoscopic tracheal occlusion. Ultrasound Obstet Gynecol. 2009;34(4):424-9.

21. Boulton SL, Mckenna DS, Cly GC, et al. Cardiac axis in fetuses with abdominal wall defects. Ultrasound Obstet Gynecol. 2006;28(6):785-8.

22. Lllanes $S$, Hunter $A$, Evans $M$, et al. Prenatal diagnosis of echogenic lung: evolution and outcome. Ultrasound Obstet Gynecol. 2005;26(2):145-9.

23. Zhao Y, Abuhamad S, Sinkovskaya E, et al. Cardiac axis shift within the cardiac cycle of normal fetuses and fetuses with congenital heart defect. Ultrasound Obstet Gynecol. 2015;46(5):558-63.

24. Voronov DA, Alford PW, Xu G, Taber LA. The role of mechanical forces in dextral rotation during cardiac looping in the chick embryo. Dev Biol. 2004; 272(2):339-50

25. Vigneswaran TV, Kametas NA, Zinevich Y, et al. Assessment of cardiac angle in fetuses with congenital heart disease at risk of 22q11.2 deletion. Ultrasound Obstet Gynecol. 2015;46(6):695-9.

26. Shanshen E, Rosenberg J, Van Bergen AH. Identification of novel congenital heart disease candidate genes using chromosome microarray. Pediatr Cardiol. 2018;39(1):148-59.

Ready to submit your research? Choose BMC and benefit from:

- fast, convenient online submission

- thorough peer review by experienced researchers in your field

- rapid publication on acceptance

- support for research data, including large and complex data types

- gold Open Access which fosters wider collaboration and increased citations

- maximum visibility for your research: over $100 \mathrm{M}$ website views per year

At $\mathrm{BMC}$, research is always in progress.

Learn more biomedcentral.com/submissions 